\title{
Superkondensatorowa elektropulsacyjna metoda zwiększenia odporności zmęczeniowej wyrobów wykonanych z blachy austenitycznej
}

\author{
Supercapacitors electropulsing method for improvement \\ the fatigue resistance of the austenitic steel sheets
}

\section{Streszczenie}

Celem prowadzonych badań było zbadanie wpływu zastosowania pulsacyjnego przepływu prądu o dużej gęstości (z wykorzystaniem zasilacza superkondensatorowego) na żywotność zmęczeniową badanych próbek. W tym celu przeprowadzono analizy eksperymentalne dla grupy próbek niepoddanych pulsacji prądowej i po ekspozycji prądowej. W pracy przedstawiono wyniki badań dla stali austenitycznej AISI 304 (0,04\% C, 1,2\% Mn, 18,16\% Cr, 8\% Ni, 0,335\% Mo, $0,041 \% \mathrm{Si}$ ) w zakresie ograniczonej wytrzymałości zmęczeniowej. Eksperymenty prowadzono na próbkach płaskich z karbem (SENT - Single Edge Notched Tension Specimen) U-kształtnym wykonanym metodą elektroiskrowego drążenia $\left(\mathrm{W}=15 \mathrm{~mm}, \mathrm{t}=0,5 \mathrm{~mm}, \mathrm{a}_{0}=2,5 \mathrm{~mm}\right)$. Zastosowano impulsy prądowe dodatnie o różnych czasach trwania oraz częstotliwościach. Badania przeprowadzono na pulsatorze hydraulicznym MTS 810, sterowano stałą amplitudą siły $F_{\max }=1100 \mathrm{~N}$. Uzyskane, wstępne wyniki zachęcają do dalszych analiz i studiów nad szeregiem czynników pozwalających wykorzystać zjawisko elektropulsacji wysokoprądowej w kontekście zwiększania trwałości zmęczeniowej narzędzi lub wyrobów otrzymywanych obróbką plastyczną.

Słowa kluczowe: odporność zmęczeniowa; wykres Wöhlera; metoda obróbki elektropulsacyjnej; stal austenityczna AISI 304

\begin{abstract}
The purpose of the study was to investigate the effect of the use of high density pulsed current (using supercapacitor) on the fatigue life of the tested specimens. For this purpose, experimental analyses were carried out for a two group of samples: without current pulsation and after current exposure. The results of the study for AISI 304 steel (0.04\% C, $1.2 \% \mathrm{Mn}, 18.16 \% \mathrm{Cr}, 8 \% \mathrm{Ni}, 0.335 \% \mathrm{Mo}, 0.041 \% \mathrm{Si})$ for fatigue strength were presented. The experiments were performed on single edge notched tensile specimen (SENT) with U-shaped electro-drilling $(W=15 \mathrm{~mm}, t=0.5 \mathrm{~mm}$, $\mathrm{a}_{0}=2.5 \mathrm{~mm}$ ). Positive current pulses with different durations and frequencies were used. The tests were carried out on a hydraulic pulsator MTS 810 , controlled by a constant force amplitude $F_{\max }=1100 \mathrm{~N}$. Obtained initial results encourage for further analyzes and studies with a number of factors that allow the use of high current electricity in the context of increasing the fatigue life of tools or products obtained by plastic metal forming.
\end{abstract}

Keywords: fatigue resistance; Wöhler diagram; electropulsing metod; AISI 304 steel

\section{Wstęp}

Zagadnienie wpływu zewnętrznego pola magnetycznego i elektrycznego na odpowiedź mechaniczną materiału określana jest mianem efektu pól krzyżowych.

Do najbardziej znanych i rozwijanych zagadnień tego typu należy zaliczyć m.in. efekt magnetomechaniczny w postaci wykorzystania zjawiska odwrotnej magnetostrykcji [1]. Takie wykorzystanie pola magnetycznego i mechanicznej odpowiedzi materiału pozwala na uzyskanie szeregu interesujących zastosowań tego zagadnienia w praktyce inżynierskiej - np. w postaci kamery magnetowizyjnej $[2,3]$.
Relatywnie mało poznanym zjawiskiem krzyżowym jest efekt wpływu zewnętrznego pola elektrycznego na właściwości mechaniczne badanego materiału. Zjawisko to nosi nazwę zjawiska elektroplastyczności i już w roku 1954 Cortan i Baret [4] obserwowali wpływ pola elektrycznego na granice ziaren materiału metalicznego. Inna grupa autorów prac $[5,6]$ dokumentowała wpływ tego zjawiska na ciągliwość materiału i jego zdolność do deformacji. Na tym tle ocena wpływu tego zjawiska na właściwości zmęczeniowe wydaje się być interesująca. Interesującym wykorzystaniem tego zjawiska

Dr hab. inż. Zbigniew Zimniak, prof. PWr; dr inż. Grzegorz Lesiuk; dr inż. Wojciech Wiśniewski - Politechnika Wrocławska.

Autor korespondencyjny/Corresponding author. zbigniew.zimniak@pwr.edu.pl 


\begin{tabular}{|c|c|c|c|c|c|c|c|c|c|c|c|c|c|}
\hline \multicolumn{10}{|c|}{ Skład chemiczny w [\%] } \\
\hline $\mathbf{C}$ & $\mathbf{M n}$ & $\mathbf{S i}$ & $\mathbf{P}$ & $\mathbf{S}$ & $\mathbf{C r}$ & $\mathbf{N i}$ & $\mathbf{M o}$ & $\mathbf{V}$ & $\mathbf{C u}$ & $\mathbf{A l}$ & $\mathbf{T i}$ & $\mathbf{W}$ & $\mathbf{N}$ \\
\hline 0,0403 & 1,1000 & 0,4100 & 0,0437 & 0,0044 & 18,1600 & 7,9800 & 0,3350 & 0,0938 & 0,3290 & 0,0023 & 0,0089 & 0,0437 & 0,1360 \\
\hline
\end{tabular}

jest możliwość „leczenia pęknięć” w stalowych elementach konstrukcyjnych [7]. Jednak niewiele miejsca poświęca się w literaturze na wykorzystanie tego zjawiska w badaniach zmęczeniowych, dlatego też niniejsza praca przedstawia wstępne wyniki badań autorów w tym zakresie. W kontekście technologicznym wyroby otrzymywane za pomocą różnych metod obróbki plastycznej oraz stosowane w tych procesach narzędzia podlegają bardzo często działaniu obciążeń zmęczeniowych. Zwiększenie trwałości zmęczeniowej staje się kluczowym zagadnieniem np. w przemyśle lotniczym, czy też eksploatacji narzędzi kuźniczych.

\section{Materiał i metoda}

Obiektem badań były próbki płaskie z karbem ze stali austenitycznej AISI 304 przedstawione na rysunku 1 o składzie chemicznym zamieszczonym w tablicy I.

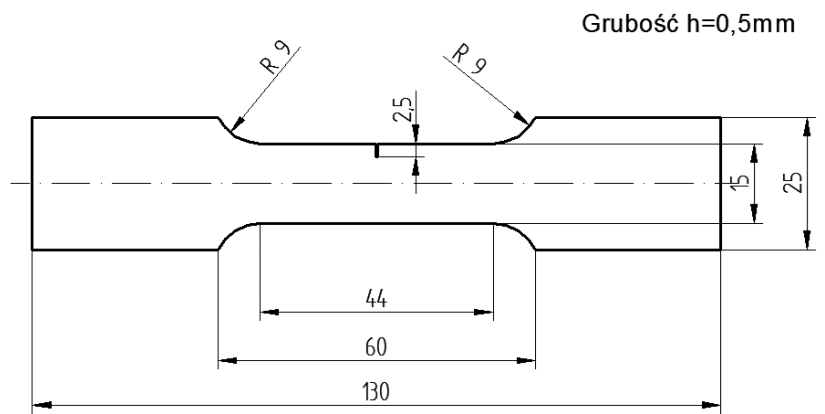

Rys. 1. Rysunek wykonawczy próbek płaskich używanych podczas eksperymentu

Fig. 1. Working drawing of flat samples used during the experiment

Do badań przygotowano próbki z bocznym koncentratorem naprężeń $\left(k_{t}=5,88\right)$ obliczonym zgodnie z pracą [8]. Badania wytrzymałościowe przeprowadzono na pulsatorze hydraulicznym MTS 810 . Maszyną sterowano ze stałą amplitudą siły $F_{\max }=1100 \mathrm{~N}$. Widmo obciążenia miało charakter sinusoidalny o współczynniku asymetrii cyklu $R=0,1$. Podczas badań rejestrowano amplitudy sygnału siły i odpowiadające jej amplitudy odkształcenia oraz liczbę cykli. W badaniach zastosowano specjalnie opracowany generator impulsów wysokoprądowych działający z zastosowaniem superkondensatorów.

Superkondensatory działają na zasadzie wykorzystania zjawiska podwójnej warstwy Helmholtza, która stanowi obszar na granicy dwóch faz odznaczający się statystycznie nierównomiernym rozmieszczeniem elektronów lub jonów w obu fazach. Wielkie pojemności uzyskiwane są wykorzystując bardzo dużą powierzchnię styku materiału elektrod węglowych (pojemności są ok. 10000 razy większe niż tradycyjnych kondensatorów). Największymi zaletami superkondensatorów są: wysoka moc impulsowa, wysoka gęstość energii, czas życia, wysoka sprawność (od 84 do 95\%). Zaletą superkondensatorów jest też liczba cykli pracy, która może wynosić nawet ponad milion.

Najważniejsze parametry generatora prądowego to: maksymalne napięcie pracy $2,7 \mathrm{~V}$, pojemność banku kondensatorów $14000 \mathrm{~F}$, impedancja pojedynczego kondensatora $<200 \mu \Omega$, maksymalna wartość prądu impulsowego $15 \mathrm{kA}$. Zastosowano całkowicie elektroniczne przełączanie kondensatorów z użyciem tranzystorów MOSFET. Generator prądowy do realizacji procesów elektropulsacji pokazano na rysunku 2. Rysunek 3 przedstawia realizację sposobu doprowadzenia prądu do próbki.

Prąd do próbki dostarczano za pomocą miedzianych przewodów oraz zacisków śrubowych. Zastosowano impulsy prądowe prostokątne dodatnie o parametrach: czas trwania impulsu $t_{i}$ oraz okres $t_{0}$ (rys. 4). Parametry prądowe dla poszczególnych próbek dla całkowitego czasu próby $7 \mathrm{~s}$ i okresu równego $1 \mathrm{~ms}$ : próbka $1-\mathrm{t}_{\mathrm{i}}=200 \mu \mathrm{s}$, próbka $2-\mathrm{t}_{\mathrm{i}}=50 \mu \mathrm{s}$. $\mathrm{W}$ ten sposób przygotowano do badań dwie grupy próbek: bez ekspozycji prądowej i po ekspozycji prądowej - zrealizowanej po określonej liczbie cykli odpowiadającej fazie nukleacyjnej sub-mikro pęknięć.

\section{Wyniki badań i dyskusja}

W początkowej fazie badań przeprowadzono statyczną próbę rozciągania próbki płaskiej z karbem przedstawionej na rysunku 1. Eksperyment sterowano stałą prędkością

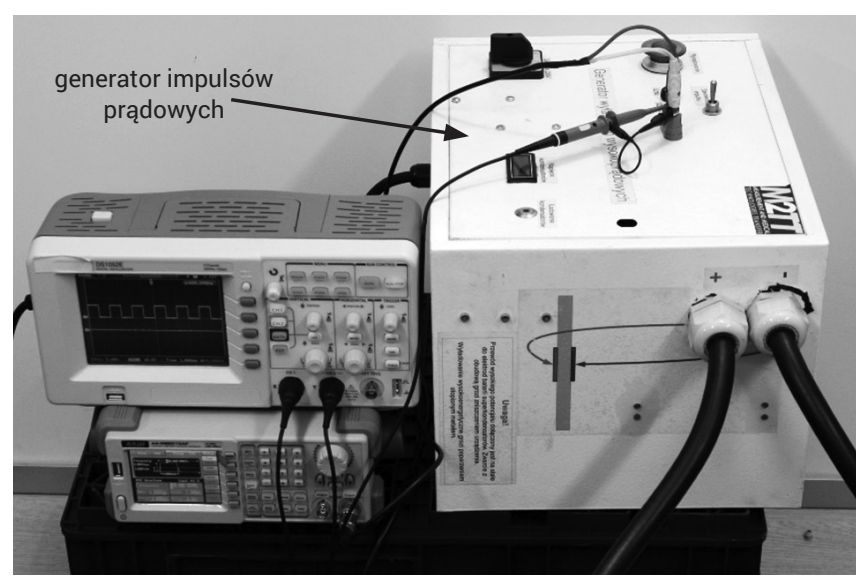

Rys. 2. Superkondensatorowy generator prądowy

Fig. 2. Supercondenser current generator

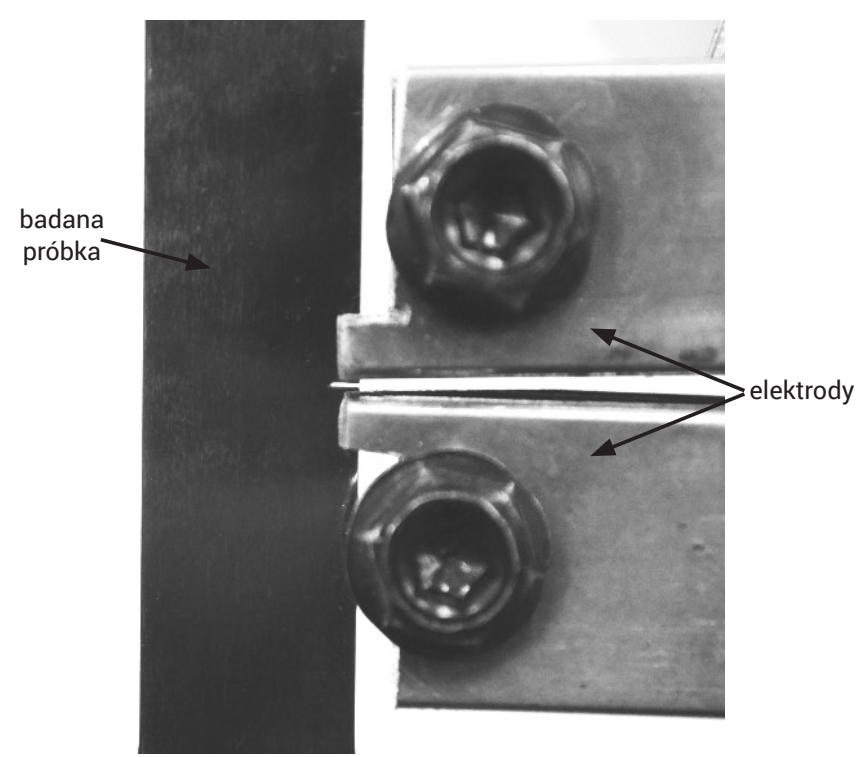

Rys. 3. Próbka wraz z elektrodami doprowadzającymi prąd Fig. 3. Sample with electrodes that supply current 


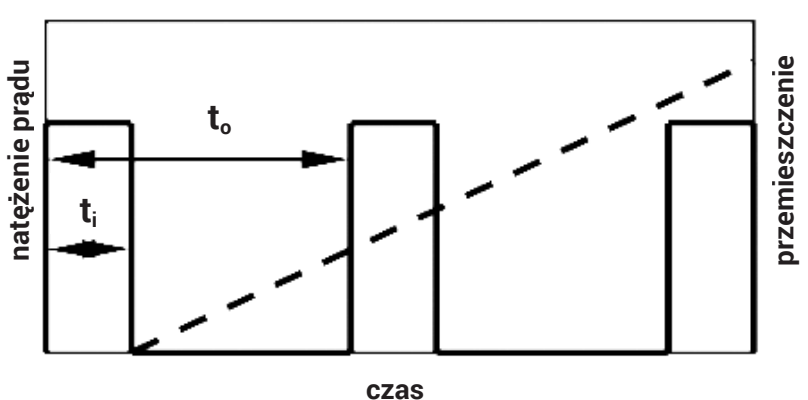

Rys. 4. Parametry prądu impulsowego

Fig. 4. Impulse current parameters

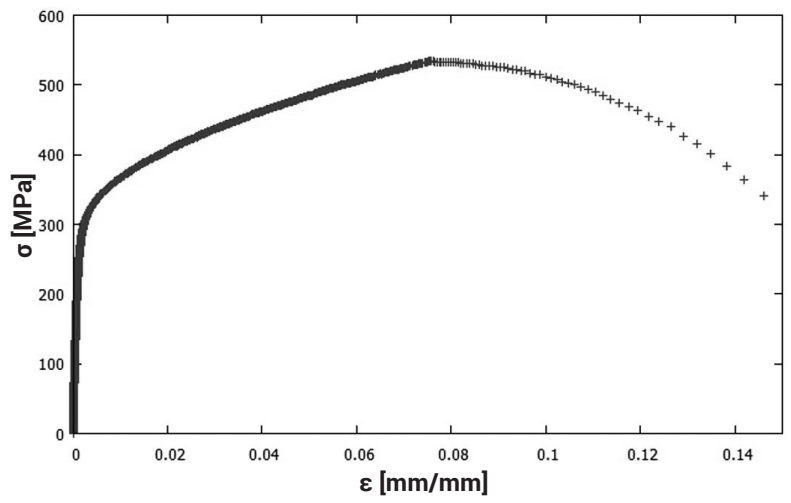

Rys. 5. Statyczna próba rozciągania próbki z karbem $k_{t}=5,88$, stal AISI 304

Fig. 5. Static sample tensile test with notch $\mathrm{k}_{\mathrm{t}}=5.88$, stal AISI 304

Tablica II. Żywotność próbek Table II. The viability of the samples

\begin{tabular}{|c|c|c|c|}
\hline $\begin{array}{c}\text { Próbka 1 } \\
\text { bez prądu }\end{array}$ & $\begin{array}{c}\text { Próbka 2 } \\
\text { bez prądu }\end{array}$ & $\begin{array}{c}\text { Próbka 3 } \\
\text { z prądem }\end{array}$ & $\begin{array}{c}\text { Próbka 4 } \\
\text { z prądem }\end{array}$ \\
\hline$N_{f}=145912$ & $N_{f}=156362$ & $N_{f}=173268$ & $N_{f}=174777$ \\
\hline
\end{tabular}

przyrostu siły, $60 \mathrm{~N} / \mathrm{s}$ co odpowiadało przyrostowi naprężenia $10 \mathrm{MPa} / \mathrm{s}$. Dzięki próbie statycznej (rys. 5) wstępnie ustalono progowe wartości sił, którymi należało obciążać próbkę podczas badań cyklicznych.

Na rysunku zestawiono wyniki pomiarowe z badań zmęczeniowych stali AISI 304 w skali podwójnie logarytmicznej. Po wyznaczeniu krzywej Wöhlera (rys. 6) wybrano jeden poziom, dla którego siła wynosiła $F_{\max }=1100 \mathrm{~N}$ i na tym poziomie przebadano jeszcze dwie próbki z przerwą w badaniu, w której próbki były poddawane działaniu prądu, po czym badania kontynuowano aż do zniszczenia. W sumie dla progu $1100 \mathrm{~N}$ przebadano cztery próbki, nr 1 i 2 obciążano do zniszczenia, a próbki nr 3, 4, z przerwą na ekspozycję prądową.

W tablicy II zestawiono liczbę cykli do zniszczenia dla każdej z próbek.

$\mathrm{Na}$ podstawie danych uzyskanych z eksperymentu powyższej tabeli można ocenić, że żywotność próbek po ekspozycji prądowej wzrosła (próbki 3 i 4).

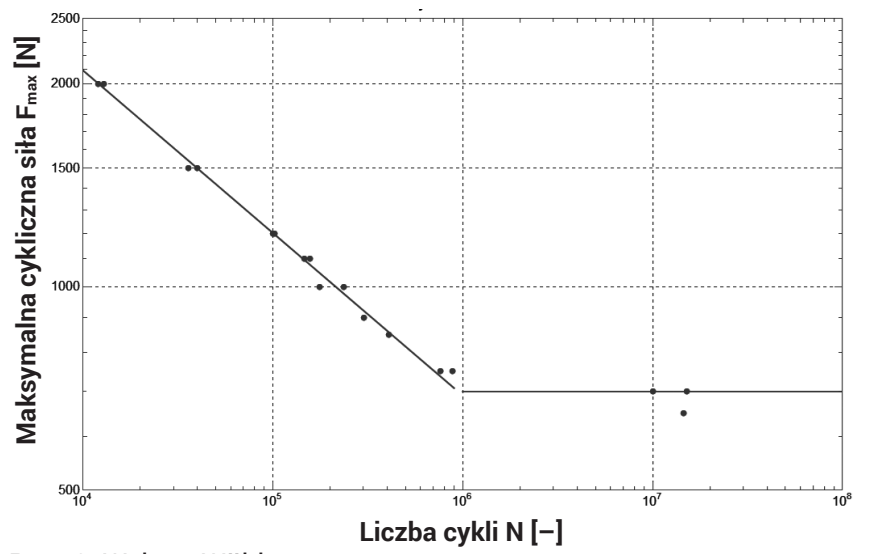

Rys. 6. Wykres Wöhlera

Fig. 6. Wöhler diagram

\section{Podsumowanie i wnioski}

W pracy zaprezentowano wstępne wyniki badań zmęczeniowych wybranych próbek poddanych ekspozycji prądowej celem uzyskania informacji o możliwościach zwiększania żywotności zmęczeniowej wywołanej stymulacją prądową. Stymulacja prądowa miała na celu inicjację zjawiska elektroplastyczności. W licznych pracach udokumentowano pozytywny wpływ tego

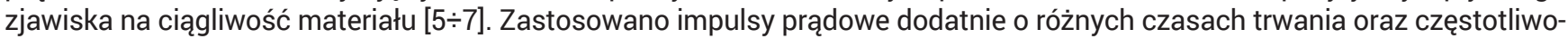
ściach. Badania przeprowadzono na pulsatorze hydraulicznym MTS 810, sterowano stałą amplitudą siły $F_{\max }=1100 \mathrm{~N}(R=0,1)$. Rejestrowana liczba cykli do zniszczenia w grupie próbek po ekspozycji prądowej była większa niż w przypadku próbek niepoddanych ekspozycji prądowej (przeciętnie o ok. 11\%).

Zakres dalszych prac badawczych koncentruje się na ocenie zmian temperatury i jej wpływu na mikrostrukturę materiału w trakcie ekspozycji prądowej. Kolejnym istotnym elementem będzie próba (statystycznie ważna) oceny wpływu ekspozycji prądowej na żywotność próbek w zróżnicowanych warunkach obciążeniowych.

Uzyskane, wstępne wyniki zachęcają do dalszych analiz i studiów nad szeregiem czynników pozwalających wykorzystać zjawisko elektropulsacji wysokoprądowej w kontekście zwiększania trwałości zmęczeniowej narzędzi lub wyrobów otrzymywanych obróbką plastyczną. Perspektywy aplikacyjne tego zjawiska wiążą się także z możliwością "leczenia pęknięć" w cienkościennych konstrukcjach metalowych - wymaga to jednak ugruntowanych badań o charakterze poznawczym.

Prace eksperymentalne zostały współfinansowane ze środków własnych Katedry Mechaniki i Inżynierii Materiałowej w ramach realizowanych badań podstawowych i aplikacyjnych zaawansowanych technologicznie rozwiązań z zakresu inżynierii materiałowej i mechaniki

\section{Literatura}

[1] Zimniak Z., Hankiewicz S.: Badania magnetyczne procesów tłoczenia blach, Obróbka Plastyczna Metali 17, 2006, s. 25-31.

[2] Kaleta J., Lewandowski D., Wiewiórski P.: 3D Magnetovision Scanner as a Tool for Investigation of Magnetomechanical Principles, Solid State Phenomena, Vol. 154, 2009, pp. 181-186.

[3] Kaleta J. Wiewiórski P. Construction of magnetic scanner for application in experimental mechanics, materiały konferencyjne 26th Danubia Adria Symposium on Advances in Experimental Mechanics, 23-26.09.2009, Leoben, Austria.
[4] Cohen M.H., Barrett C.S.: Physical Review B 95, 1954, pp. 1094-1095.

[5] Machlin E.S.: Journal of applied physics 30, 1959, pp. $1109-1110$.

[6] Troitskii O.A, Likhtman V.I.: Akademiya nauk SSSR 148, 1963, pp. 332-334.

[7] Song H., Wang Z.J.: Microcrack healing and local recrystallization in pre-deformed sheet by high density electropulsing, Materials Science and Engineering: A, Volume 490, Issues 1-2, 25 August 2008, Pages 1-6, ISSN 0921-5093, http:// dx.doi.org/10.1016/j.msea.2007.12.037.

[8] Pilkey D.: Stress concentration factors. A Wiley-Interscience Publication, 1997. 